\title{
Middle-Aged Couples' Exchanges of Support with Aging Parents: Patterns and Association with Marital Satisfaction
}

\author{
Jeong Eun Lee ${ }^{\mathrm{a}}$ Steven H. Zarit ${ }^{\mathrm{a}}$ Michael J. Rovine ${ }^{\mathrm{a}}$ Kira S. Birditt ${ }^{\mathrm{b}}$ \\ Karen L. Fingerman ${ }^{c}$ \\ ${ }^{a}$ Department of Human Development and Family Studies, Pennsylvania State University, University Park, Pa., \\ ${ }^{b}$ University of Michigan, Ann Arbor, Mich., and ' ${ }^{\mathrm{D}}$ epartment of Child Development and Family Studies, \\ Purdue University, West Lafayette, Ind., USA
}

\section{Key Words}

Intergenerational support $\cdot$ Aging parents $\cdot$ Middle-aged

couples $\cdot$ Marital satisfaction

\begin{abstract}
We examined the context of intergenerational support exchanges with aging parents and its association with middleaged couples' marital satisfaction. A sample of 197 middleaged couples reported support they gave to and received from their parents $(n=440)$. Results indicated that couples provided more total support to and received more from their parents as a function of number of living parents, but the amount of support each parent received ('parent-adjusted support') was lower when there were more living parents. The amount of support given to and received from parents had no association with the couple's marital satisfaction, but discrepancies in support given to and received from parents did have a significant association with marital satisfaction. Husbands who gave more support to their living parent(s) than their wives reported lower marital satisfaction. A similar effect on marital satisfaction was found for wives who gave
\end{abstract}

more support to their living parents than their husbands. These findings contrast with caregiving studies where amount of support affected marital satisfaction and suggest that inequalities in involvement with parents may be a critical dimension in marriages of midlife adults.

Copyright $\odot 2011$ S. Karger AG, Basel

Research on family patterns of intergenerational exchanges has focused on questions such as which siblings in a family are most likely to be involved in exchanges with aging mothers [1] or which grown children are most likely to receive support from their parents [2]. Many middle-aged children who assist a parent are themselves married, but little attention has been given to how much help the couple as a unit give or the implication of differences in the help that each person gives to his/her own parents for marital satisfaction. At the same time, older parents may continue to provide support and assistance to their middle-aged children. Although family lore is rife with examples of how the help that parents give their grown children can produce jealousy and conflict in a

\section{KARGER}

() 2011 S. Karger AG, Basel

Fax +41613061234 E-Mail karger@karger.ch www.karger.com www.karger.com/ger
Jeong Eun Lee

Department of Human Development and Family Studie

Pennsylvania State University, S110 Henderson Building

University Park, PA 16802 (USA)

Tel. +1 773516 1653, E-Mail jzl174@ @su.edu 
married couple, there has been little empirical evidence of whether the amount of support provided or differences in help given to and received from each set of parents is related to marital satisfaction.

In this study, we examined the patterns of support to parents and their implications for middle-aged couples' marital satisfaction. We considered first whether the total amount of support that couples exchange with all parents and the help that each parent receives (parent-adjusted help) varied by the number of living parents. We then investigated whether the total amount of intergenerational support exchanged or the difference between a husband and wife in the amount of help given to and received from parents was associated with marital satisfaction of husbands and wives.

\section{Support Exchanges between Middle-Aged Couples and Aging Parents}

Most empirical research on intergenerational support has relied on the reports of a single person, usually a middle-aged daughter, who discusses the help she gives to her parents or parents-in-law, and who may also give information about how much help other family members provide $[3,4]$. Given that much of the support middle-aged people give to their parents occurs in the context of married life, a different picture may emerge when considering the help that each marital partner gives to and receives from his or her parents.

The number of living parents involved in exchanges with a given couple may influence the amount of time and resources involved in these exchanges [5]. Although this point has not previously been addressed when considering the help that adult children provide their aging parents, there is literature that demonstrates a relation between the support parents give to young children and family size. In what is termed 'resource depletion,' children in larger families receive less support from parents than children in smaller families $[6,7]$. In one of the few studies of resource depletion focusing on adulthood, grown children in larger families received fewer resources from parents than grown children from smaller families [8]. These results suggest that family resources are finite. An alternative perspective, resource expansion, suggests that middle-aged adults are able to expand available time and energy to meet increasing needs, whether due to family size and/or specific life problems. This perspective has also received some support in the literature $[2,9]$.

Middle-Aged Couples' Exchanges of Support with Aging Parents
Given these conflicting theoretical stances, we considered two ways that the number of living parents may affect the amount of help a couple gives. First, we considered whether having more living parents might increase the amount of demand on the couple as a whole. Specifically, we posited that when there are more living parents, the total support that a couple gives would be greater (hypothesis 1). Second, since resources are finite, we expected that each parent would receive less support when a couple has a greater total number of living parents. Thus, the parent-adjusted support (total support divided by number of living parents) that parents receive from children would be lower when the couple has more living parents (hypothesis 2).

Prior studies have also focused primarily on exchanges of support that are transmitted in one direction (from adult children to frail aging parents). According to the social exchange theory [10], however, aged parents tend to reciprocate the exchanges of support they have with their grown children. Indeed, studies have shown that that middle-aged offspring not only provided support to their aging parents, but also received various types of support from their parents [11-13]. As a result, just as a couple may give more total support when they have a larger number of living parents, they may receive more total support when they have more living parents. Thus, we expected that the total amount of support aging parents provide to middle-aged couples will increase as a function of number of living parents (hypothesis 3 ).

\section{Support Exchanges with Parents and Their Association with the Middle-Aged Couples' Marital Satisfaction}

According to the family systems theory, conflicts between husbands and wives often erupt as a result of a third party in the family [14]. Both in popular culture and in research, parents-in-law are frequently identified as the source of marital disputes among middle-aged couples [15]. The support that one member of a couple gives or receives from parents may be perceived as interference or overinvolvement, thus leading to increased tensions in the marriage.

Much of the literature has been guided by a stress-burden model whereby increased support to parents would affect marital interactions and satisfaction. Although the stress-burden model has been helpful in highlighting crucial aspects of support exchanges on marital satisfaction, its focus has been criticized as too narrow $[16,17]$.

Gerontology 2012;58:88-96 
Some researchers believe that intergenerational support given to and received from aging parents can be viewed as a midlife developmental task that offers opportunity for psychological growth and which helps them develop a more mutual relationship with parents $[18,19]$. This perspective suggests that providing and receiving support are normative developmental tasks for married adults which do not necessarily have a negative impact on their marriage.

Empirical findings on the impact of providing support to aging parents on marital satisfaction are mixed. Some studies have shown that caring for dependent parents has no significant effect on the marital satisfaction of adult caregiver daughters [20]. Other studies have found a significant association between higher caregiving burden for aging parents and greater stress that adult offspring felt in their marriage [21,22]. As these examples indicate, most studies that have looked at this issue have focused on caregiving situations, where one parent needed intensive help for disabilities. It is unclear whether normative types of support would have a similar negative association with middle-aged couples' marriages. However, given the multiple roles and responsibilities of middle-aged couples, the amount of support given to and received from aging parents could contribute to marital distress. Prior work on this issue has been limited by relying only on one informant from the couple, usually a wife [23], without considering whether and how much assistance or support the other spouse gave to parents, or how the combination of support to each set of parents might be associated with marital satisfaction.

In the present study, we interviewed both the husband and wife about the support given to and received from parents and their marital satisfaction. Consistent with prior findings that more exchanges with parents lead to marital dissatisfaction, we hypothesized that couples providing more help overall to parents would report lower marital satisfaction (hypothesis 4). As previous work has not addressed the implications of receiving support from parents and marital satisfaction, we examined that issue without a specific hypothesis (research question 1).

In addition to the effect of the total amount of support that a couple gives to parents, we also considered if disparities between husband and wife in the amount of help given and received to parents could lead to lower marital satisfaction. Some studies found that husbands and wives often compare each other's involvement in family work as a reference point [24]. Other studies found that perceived unfairness in family work has an association with marital dissatisfaction $[25,26]$. In the same vein, dispari- ties in each spouse's involvement with his or her own aging parents may also create resentment, jealousy or competition. We hypothesized that disparities in support exchanged with aging parents will be associated with lower marital satisfaction (hypothesis $5 \mathrm{a}$ ). Given that disparity will have different implications for husbands and wives, we also examined whether the effect of disparity differs for husbands and wives (hypothesis $5 b$ ).

\section{Methods}

\section{Participants}

The sample consists of married couples aged 40-60, who were drawn from the larger sample of the Family Exchange Study. Participants were recruited from the Philadelphia Primary Metropolitan Statistical Area, encompassing five counties in southeastern Pennsylvania and four counties in New Jersey [27], including urban, suburban and rural areas. Participants were identified in a two-step process. First, a target participant was identified who was between the ages of 40 and 60 and had at least one living parent and at least one living child 18 years of age or older. Potential participants were contacted by telephone using a sampling method stratified by age (aged 40-50 and 51-60) using a list purchased from Genesys Corporation and random digit dialing within regional area codes. An interviewer administered the screening instrument to determine if the household had an eligible target respondent. When an eligible person was identified, the interviewer invited him or her to participate in the study.

Target participants completed a telephone interview lasting approximately $1 \mathrm{~h}$ that addressed the support they exchanged and their relationships with their offspring and aging parents. Of the 845 eligible targets, 633 (75\%) agreed to be interviewed. During this interview, target participants were asked if the research team could contact children who were 18 years of age or older, their living parents, and a spouse if the target was married and the couple were the shared biological parents of the grown children.

Among 633 target participants, 335 (51\%) were married at the time of the interview, and 287 (86\%) of them agreed to let us contact their spouse. Among those 287 spouses, 197 (71\%) agreed to be interviewed. Table 1 presents demographic characteristics, including age, ethnicity, work status, education, number of children, self-rated health, parents' functioning (activities of daily living) and living numbers of parents for the 197 dyads. As seen in table $1,17.5 \%$ of the wives' parents and $16.5 \%$ of the husbands' parents required assistance with instrumental activities of daily living, indicating that most parents of these couples were relatively independent.

\section{Measures}

Dependent Variables: Marital Satisfaction

Participants rated the overall quality of the relationship with their spouse on a 5 -point scale from 1 (excellent) to 5 (poor). This single item was adapted from an item used in the Americans' Changing Lives survey [28]. The item was reverse coded so that higher scores represented greater marital satisfaction. The mean was $4.17(\mathrm{SD}=0.90)$ for wives and $4.25(\mathrm{SD}=0.91)$ for husbands, indicating high marital satisfaction. 
Table 1. Demographic characteristics of the participants, husbands and wives

\begin{tabular}{lcc}
\hline & $\begin{array}{l}\text { Husbands } \\
(\mathrm{n}=197)\end{array}$ & $\begin{array}{l}\text { Wives } \\
(\mathrm{n}=197)\end{array}$ \\
\hline Means and standard deviations & & \\
Age & $52.58(5.14)$ & $50.74(4.72)$ \\
Years of education & $14.76(1.94)$ & $14.46(2.22)$ \\
Rating of health & $3.71(9.94)$ & $3.63(0.96)$ \\
Number of parents & $1.07(9.67)$ & $1.21(0.67)$ \\
Number of children & \multicolumn{2}{c}{$2.59(1.21)$}
\end{tabular}

\section{Proportions}

Ethnicity: white

$\begin{array}{ll}0.89 & 0.89 \\ 0.81 & 0.61 \\ 0.17 & 0.16\end{array}$

Work status: employed full time

0.17

0.16

Standard deviation in parentheses. ADL $=$ Activities of daily living. ${ }^{\text {a }} 1$ = Poor; 2 = fair; 3 = good; 4 = very good; 5 = excellent.

Independent Variables: Support Exchanges

Participants rated how often they provided six types of support to each of their own living parents: emotional, practical assistance, socializing, advice, financial support and talking about daily events. The first five items were derived from the Social Support Resources Index [29]. The final item was added based on preliminary studies of intergenerational support [2]. Frequency of support for each item was scored on an 8-point scale that ranged from 1 (less than once a year or not at all) to 8 (daily). As in prior studies $[2,30]$, we summed the six items to create a score for how much support participants gave to each living parent.

We then derived three other support scores. First, we summed the amount of support the couple gave to and received from all living parents. Given that the total amount of support couples provided and received from aging parents was relevant to our hypothesis as well as dyadic analysis, we considered the total amount of support instead of the support a husband and a wife provided or received from parents separately. This indicator represents, in effect, the total output and input of support to and from all parents. Second, to test the resource depletion hypothesis, we divided the total support the couple reported by the number of living parents to obtain a score of parent-adjusted support (i.e. how much support each parent received on average). Third, to examine the relation between the difference in amount of support given by a husband and wife to their respective parents and marital satisfaction, we created a disparity score by subtracting the total amount of support that a husband gave to his parents from the total amount of support that his wife gave to her parents. A positive disparity score indicates a wife gives more support to her parents compared to her husband, while a negative score indicates her husband gives more help to his parents than she does to hers.

In addition, we asked if participants received support from parents in the same six areas. As with support given, we computed the total amount of support the couple received from parents, the parent-adjusted support (how much support received on average from each living parent) and the disparity of support received within the couple.

Middle-Aged Couples' Exchanges of Support with Aging Parents

\section{Data Reduction}

Prior to conducting analyses, exploratory factor analysis was used to establish subscales of social support. Separate factor analyses were conducted for husbands', wives', aging mothers' and fathers' social support. Items included the six types of support (i.e. emotional, practical, advice, financial support, talking about daily lives and socializing). The results indicated that the factors loaded on a single scale. This scale demonstrated satisfactory reliability, with alphas ranging from 0.83 to 0.89 .

\section{Control Variables}

To control for the possibility that giving and receiving support are due to demographic characteristics or mental and physical robustness of aging parents and/or their adult children, we measured a variety of demographic, health and individual difference variables (e.g. proximity to parents, number of adult children, education). Age was controlled in each analysis to take into account the possibility that older individuals give less and receive more. Geographic distance between the parties may influence the amount of support and, then, marital relationship of middle-aged couples [1]. Thus, distance to each parent was included as a covariate. The measure of distance to parents was skewed, so we performed a log-linear transformation. Education and income were considered as covariates since individuals with higher education and income tend to exchange more support with aging parents [31]. Poor health status could lower the amount of support given and increase the amount received [16]. Thus, self-rated health was included as a covariate. Middle-aged adults provide greater total amounts of assistance to children when they have a larger number of children [2]. As a proxy for the amount of support middle-aged couples provide for children, the present analysis used number of children as a covariate.

\section{Analysis Plan}

Covariates

As a first step, we estimated bivariate associations between potential covariates and amount of support provided and received from aging parents. Significant associations were found for participant age and health; therefore, these variables were included in the analyses. Other potential covariates, including number of children, income, education and distance to parents' home were not significantly associated with the total amount of support or parent-adjusted support. Since covariates that are not associated with the dependent variable may generate spurious associations between variables [32], these nonsignificant variables were not included in subsequent analyses.

\section{One-Way ANCOVA}

Our first analyses considered support at the level of the couple. One-way ANCOVAs (GLM) were used to examine if the total amount of support and the parent-adjusted support the couple provided and received from parents varied as a function of the number of living parents (hypotheses 1, 2 and 3).

\section{Multilevel Modeling}

We next used multilevel models to examine the effects of total support given and disparities within couples in the amount of support they each exchanged with parents on individuals' marital satisfaction nested within couples (hypotheses $4,5 \mathrm{a}, 5 \mathrm{~b}$ and research question 1). Separate models were computed for the sup- 
Table 2. Mean (adjusted for covariates) of total support and parent-adjusted support from married couples to parents by number of parents $(n=197)$

\begin{tabular}{|c|c|c|c|c|}
\hline & $\begin{array}{l}1 \text { parent } \\
(\mathrm{n}=40)\end{array}$ & $\begin{array}{l}2 \text { parents } \\
(\mathrm{n}=81)\end{array}$ & $\begin{array}{l}3 \text { parents } \\
(\mathrm{n}=56)\end{array}$ & $\begin{array}{l}4 \text { parents } \\
(\mathrm{n}=20)\end{array}$ \\
\hline \multicolumn{5}{|l|}{ Support provided to parents } \\
\hline Total support $\mathrm{a}^{\mathrm{a}}$ & $28.24(2.50)$ & $54.86(1.73)$ & $73.94(2.1)$ & $99.2(3.50)$ \\
\hline Parent-adjusted support to each parent ${ }^{\mathrm{a}}$ & $28.24(1.18)$ & $27.53(0.81)$ & $24.52(0.98)$ & $25.17(1.65)$ \\
\hline \multicolumn{5}{|l|}{ Support received from parents } \\
\hline Total support ${ }^{\mathrm{a}}$ & $17.72(1.86)$ & $35.96(1.27)$ & $48.32(1.56)$ & $69.86(2.62)$ \\
\hline Parent-adjusted support to each spouse & $17.39(0.83)$ & $17.97(0.57)$ & $16.01(0.69)$ & $17.4(1.17)$ \\
\hline
\end{tabular}

port that couples gave to their parents and for the support they received from their parents. In order to account for the lack of independence in the data, we computed multilevel models using the PROC MIXED procedure in SAS [33]. We estimated models that included a repeated effect that allowed errors within couples to be correlated. The models assumed that observations from a single respondent would have a covariance structure of compound symmetry (all correlations between scores are assumed to be the same). In these analyses, the couple is an upper level unit and each spouse is a lower level unit. Marital satisfaction served as a dependent variable. Each model included a fixed effect of the couple's sum (husband + wife) of support they collectively exchanged with aging parents, and disparities in support exchange. We did this because we had an interest in testing whether the total output of the couple might place strain on the marriage and/or if discrepancies in support had an effect on marital satisfaction. This approach of including both a total and discrepancy score is generally recommended in dyadic analyses [34].

Covariates included in the multilevel models were, as noted, participants' age, education, health and number of children. Lower level variables included education and health of each respondent. Upper level control variables included income. Interaction terms were included to examine whether the effects of disparities differed for husbands and wives. Prior to computing the interaction terms, we grand mean-centered continuous variables (total amount of support and disparity in support) and coded the dichotomous variable gender as 0 and 1 .

\section{Results}

The results are presented in three sections. First, we present two ANCOVA models examining whether the total and parent-adjusted amount of support vary by the number of living parents. Next, we provide the multilevel models examining whether the total amount of support and disparities in support exchanged by husbands and wives with their respective parents were related to marital satisfaction.
Total Amount of Support and Parent-Adjusted

Support Provided to Parents by Couples

The total amount of all support for parents and the parent-adjusted support given to each living parent (i.e. total amount of all support/number of living parents), adjusted for the covariates, are presented in table 2. Couples with more living parents provided more support overall $\left[F(3,187)=101.11, \mathrm{p}<0.001\right.$, partial $\left.\eta^{2}=0.62\right]$. Pairwise comparisons revealed significant differences between couples with 1, 2, 3 and 4 living parents. None of the covariates had a significant effect on the total amount of support provided to parents.

The number of living parents also had a significant main effect on the parent-adjusted support couples gave, after controlling for the covariates $[F(3,187)=3.61, \mathrm{p}<$ 0.05 , partial $=0.07]$. Couples with more living parents gave less support to each parent, compared to couples with fewer living parents. Pairwise comparisons indicated significant differences in parent-adjusted support between couples with 1 and 3 living parents, and between couples with 2 and 3 living parents. None of the covariates had significant effects on the total amount of support provided to parents.

\section{Total Amount of Support and Parent-Adjusted \\ Support Received from Parents}

We next analyzed whether the total and parent-adjusted support from aging parents to couples would change as a function of number of parents. Results are shown in table 2. As expected, the total amount of support from parents to their middle-aged children increased with the number of living parents $[F(3,189)=94.89, \mathrm{p}<0.0001$, partial $=0.66]$. Pairwise comparison revealed significant differences between couples with 1 and 2 living parents and between those with 3 and 4 living parents. The num- 
Fig. 1. Marital satisfaction and disparity in the provision of support for aging parents.

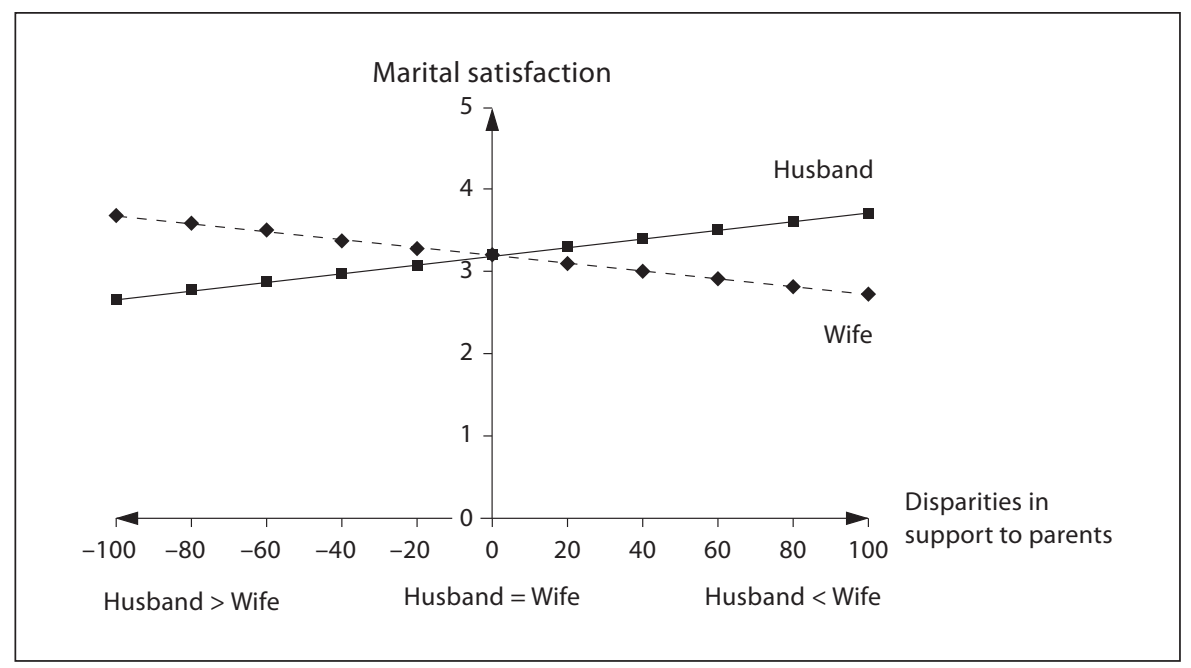

Table 3. Mixed models predicting couples' marital satisfaction from provision of support exchange and disparities in support exchange with aging parents

\begin{tabular}{|c|c|c|c|c|c|c|}
\hline \multirow[t]{2}{*}{ Predictor } & \multicolumn{3}{|c|}{$\begin{array}{l}\text { Model 1: support given } \\
\text { to aging parents }\end{array}$} & \multicolumn{3}{|c|}{$\begin{array}{l}\text { Model 2: support received } \\
\text { from aging parents }\end{array}$} \\
\hline & B & $\mathrm{SE}_{\mathrm{B}}$ & $\mathrm{t}$ & B & $\mathrm{SE}_{\mathrm{B}}$ & $\mathrm{t}$ \\
\hline Intercept & $3.29^{* * *}$ & 0.38 & 8.62 & $3.3^{* * *}$ & 0.38 & 8.73 \\
\hline Gender & -0.001 & 0.06 & -0.02 & 0.01 & 0.07 & 0.20 \\
\hline Total support & -0.002 & 0.002 & -0.75 & -0.003 & 0.002 & -0.98 \\
\hline Disparities in support & $0.006^{*}$ & 0.002 & 2.63 & 0.007 & 0.003 & 2.18 \\
\hline $\begin{array}{l}\text { Disparities* in gender } \\
\text { Covariates }\end{array}$ & $-0.01^{* * *}$ & 0.002 & -4.12 & $-0.01^{* * *}$ & 0.003 & -4.16 \\
\hline Income & 0.06 & 0.05 & 1.10 & 0.06 & 0.05 & 1.10 \\
\hline Education & 0.002 & 0.02 & 0.10 & 0.004 & 0.03 & 0.18 \\
\hline Health & $0.18^{* *}$ & 0.04 & 3.97 & $0.17^{* *}$ & 0.04 & 3.89 \\
\hline Residual & $0.42^{* * *}$ & 0.04 & & $0.43^{* * *}$ & 0.04 & \\
\hline
\end{tabular}

${ }^{*} \mathrm{p}<0.05 ;{ }^{* *} \mathrm{p}<0.01 ;{ }^{* * *} \mathrm{p}<0.001$. ber of parents, however, did not have any effect on the parent-adjusted supportfrom parents. That is, the amount of support each parent gave was not affected by the total number of living parents.

\section{The Effects of Support Exchanges on Marital}

Satisfaction of Couples

The multilevel model using total amount of support given to parents and disparities between husbands and wives in support given to parents is shown in table 3 . The total amount of support for parents was not associated with marital satisfaction for husbands or wives (hypothesis 4). Disparities in support for parents, however, had a significant effect on marital satisfaction (hypothesis $5 \mathrm{a}$ ), and the interaction of gender and disparities was also significant (hypothesis 5b).

Figure 1 presents how disparities in support provided to parents differs by gender. Disparity in support to parents is plotted along the $\mathrm{x}$-axis and husbands' and wives' marital satisfaction along the $y$-axis. As indicated above, a positive disparity score indicates a wife's higher involvement with her parents compared to her husband, and a negative disparity score indicates a husband's higher involvement with his parents compared to his wife. As illustrated in figure 1, when the disparity is larger in a positive direction (wives' involvement $>$ husbands'), the marital satisfaction of the husbands is higher and the wives' marital satisfaction is lower. Conversely, when the 
disparity score is larger in a negative direction (husbands' involvement $>$ wives'), the marital satisfaction of the wives is higher and the husbands' marital satisfaction is lower.

We also considered the possibility that the effects of disparities displayed in figure 1 simply reflect the total amount of support a husband or wife gives. A larger discrepancy might indicate that one person gives a lot of support. To test this possibility, we ran separate regressions for husbands and wives to examine if the total support each person gave or received was associated with marital satisfaction. However, we found that the amount of support given separately by husbands and wives, or the support they received, was not associated with their marital satisfaction.

Also, as shown in model 2 of table 3 , the total amount of support received from parents was not associated with marital satisfaction for both husbands and wives (research question 1). Disparities in support from parents, however, had a significant effect on marital satisfaction (hypothesis 5a). A gender $\times$ disparities interaction was also significant for support received (hypothesis $5 b$ ). The gender interaction indicates that whoever received more support from parents compared to one's spouse reported lower marital satisfaction. Among the covariates, self-rated health was significantly associated with marital satisfaction for both husbands and wives in both models.

\section{Discussion}

We examined the amounts of support middle-aged adults exchanged with parents and the effects that the total amount of support and disparities of support have on marital satisfaction. In contrast to most prior work, we included reports from couples, rather than just relying on one respondent in a marriage or reports drawn from wives and husbands not married to one another. We also looked at support given to and received from parents.

\section{Number of Parents as a Determining Factor for \\ Intergenerational Support Exchange}

We looked first at whether the number of living parents was related to the total support given and received, and the parent-adjusted support each individual parent received. The results supported both the resource expansion [2] and the resource depletion hypothesis [7]. Consistent with the resource expansion hypothesis, with more living parents, couples as a whole gave more total support to their aging parents. However, consistent with the resource depletion hypothesis, when a couple had more living parents, each parent received less support. This situation may not be problematic for the dyad under ordinary circumstances, such as observed in the current study, but middle-aged couples with more living parents may be able to commit less time and fewer resources if the needs of one parent were to increase due to health problems or other adverse circumstances. Although not examined in this study, increases in needs of children may also lead to reduced resources for other family members. The results underscored the value of considering the whole family when examining support exchanges, as well as the potential that couples may encounter competing demands when they have more living parents.

Our findings also demonstrated that there are frequent exchanges of various types of support between generations. The mean pattern indicated that each of the six types of support was exchanged once a month, with most participants reporting more frequent exchanges in at least some domains. These results expand on the finding by Fingerman et al. [2] from the same data set that shows a similar pattern of exchanges between the middle generation and their grown children. In contrast to the contingency theory that posits the need for care or other special assistance drives intergenerational exchanges [35], our findings in a predominantly healthy sample of middle-aged adults and their parents suggest that exchanging intergenerational support is part of the everyday fabric of family life. Factors such as previous patterns of exchange, family norms and affection may play critical roles in shaping these everyday exchanges, while contingency may drive support in times of increased need.

We considered the possibility that two of the support items, socializing and talking about daily lives, might represent a different type of support (companionship) that would show a different pattern of exchange. We reran our analyses without these two items and found results that were identical to the pattern observed with the full scale.

\section{Relation between the Total Amount of Support \\ Exchange and Disparities in Support Exchange on \\ Marital Satisfaction}

In contrast to caregiving studies where the amount of help given to a parent places strain on couples' marital satisfaction [21], findings from this study showed no effects of the total amount of everyday support given by the couple. In part, this finding is due to the fact that middleaged adults typically gave support on an intermittent basis, and the effects of giving may have been balanced by 
receiving support in return from their parents. As noted, middle-aged couples with more living parents also could have adjusted their use of time and resources in providing support.

On the other hand, disparities in the amount of support exchanged were associated with husbands' and wives' marital satisfaction. Whether it was the wife or husband, whichever spouse gave more support to parents and received more from parents than the other spouse reported lower marital satisfaction. These results are consistent with prior evidence that married couples often make comparisons between themselves regarding house work and other family matters [24], and that perceived unfairness in family work was negatively associated with marital satisfaction $[25,26]$.

The literature has emphasized the effects of involvement with parents on wives' marital satisfaction [20], but we found husbands to be affected in a similar way. It is also noteworthy that husbands and wives who gave less support to their own parents compared to their spouse reported higher marital satisfaction. They did not appear resentful at their spouses' greater involvement with their parents. An alternative explanation of the findings is that spouses who are less satisfied with their marriage become more involved in support exchanges with their aging parents. In fact, studies have shown that unhappily married couples tend to increase their contact with aging parents for support and companionship [36, 37]. It may also be that some husbands and wives had greater involvement with parents from the outset of their own marriage, and that the parents played a divisive role within the marriage. These findings, of course, could be better understood with longitudinal or prospective studies that investigate the link between disparity in support and marital satisfaction.

In sum, these results underscore the importance of examining both members of the couple when considering the implication of exchanges of support between middleaged adults and their parents. Further, our analysis revealed that the disparity between spouses in the support exchanged with aging parents rather than the total amount of support may have implications for their marriage.

\section{Limitations}

Several caveats should be considered in interpreting the findings of this study. First, this sample came from a single part of the country, the Philadelphia Metropolitan Statistical Area. The sample is somewhat better educated than middle-aged couples from a representative national sample, but it is similar in many other characteristics. We also cannot rule out the possibility of selection bias in which spouses agreed to participate in the study.

While we had detailed information on the support that middle-aged children gave to their own parents, we do not know how much they may also have been supporting or receiving support from their in-laws. Previous research suggests that intergenerational support is likely to be influenced by consanguinity and long-term commitments based on past reciprocities [38], but it is also known that married daughters and, perhaps to a lesser extent, married sons are also involved in providing support for their parents-in-laws [39]. Information on the extent of involvement that husbands and wives have with their parents-in-law would make a more refined assessment of the association between help given and received and couples' marital relationship.

Another limitation of this study is the measure of marital satisfaction. Although this 1-item marital satisfaction scale has been widely used in survey research, it does not have clinical norms associated with it. Thus, although the findings indicate significant association between disparity in support and marital satisfaction, we do not know if the magnitude reflects small or large differences in marital satisfaction.

Finally, because the research design was cross-sectional, we were not able to test dynamic and bidirectional relationships among the variables. Longitudinal studies could clarify whether the support given to and received from parents affects aspects of the couple's relationship or if relationship qualities may drive patterns of intergenerational support.

\section{Acknowledgement}

This study was supported by a grant from the National Institute of Aging (No. R01 AG027769), The Psychology of Intergenerational Transfers, Karen L. Fingerman, Principal Investigator.

References

1 Suitor JJ, Sechrist J, Pillemer K: Within-family differences in mothers' support to adult children in Black and White families. Res Aging 2007;29:410-435.

-2 Fingerman KL, Miller L, Birditt KS, Zarit SH: Giving to the good and the needy: parental support of adult offspring. J Marriage Fam 2009;71:1220-1233.

-3 Silverstein M, Parrott TM, Bengtson VL: Factors that predispose middle-aged sons and daughters to provide social support to older parents. J Marriage Fam 1995;57:465475 . 
4 Ingersoll-Dayton B, Starrels ME, Dowler D: Caregiving for parents and parents-in-law: is gender important? Gerontologist 1996;36: 483-491.

5 Zarit SH, Eggebeen DJ: Parent-child relationships in adulthood and later years; in Bornstein $\mathrm{MH}$ (ed): Handbook of Parenting: Children and Parenting, ed 2. Mahwah, Lawrence Erlbaum, 2002, pp 135-161.

6 Blake J: Family size and the quality of children. Demography 1981;18:421-442.

$\checkmark 7$ Downey DB: When bigger is not better: family size, parental resources, and children's educational performance. Am Sociol Rev 1995;60:746-761.

8 Davey A, Janke M, Savla J: Antecedents of intergenerational support: families in contact and families as context; in Silversten M (ed): Intergenerational Relations across Time and Place. New York, Springer Publishers, 2005.

$\checkmark 9$ Grundy E, Henretta JC: Between elderly parents and adult children: a new look at the 'sandwich generation'. Aging Soc 2006;26: 707-722.

10 Gouldner AW: The norm of reciprocity: a preliminary statement. Am Sociol Rev 1960; 25:161-178.

-11 Ingersoll-Dayton B, Neal MB, Hammer LB: Aging parents helping adult children: the experience of the sandwiched generation. Fam Relations 2001;50:263-271.

-12 Lee GR, Netzer JK, Coward GR: Filial responsibility expectations and patterns of intergenerational assistance. J Marriage Fam 1994;56:559-565.

13 Loweinstein A, Katz R, Gur-Yaish N: Reciprocity in parent-child exchange and life satisfaction among the elderly: a cross-national perspective. J Soc Issues 2007;63:865-883.

14 Bowen M: Family Therapy in Clinical Practice. New York, Jason Aronson, 1978.

15 Beaton JM, Norris JE, Pratt MW: Unresolved issues in adult children's marital relationships involving intergenerational problems. Fam Relations 2001;52:143-153.

$\checkmark 16$ Brown SL, Nesse RM, Vinokur AD, Smith DM: Providing social support may be more beneficial than receiving it: results from a prospective study of mortality. Psychol Sci 2003;14:320-327.
17 George LK: Caregiver needs and patterns of social support. J Gerontol 1990;45:S102S111.

18 Sherrell K, Newton N: Parent care as a developmental task. Fam Soc 1996;77:174-181.

19 Taylor J, Turner J: A longitudinal study of the role and significance of mattering to others for depressive symptoms. J Health Soc Behav 2001;42:310-325.

20 Suitor JJ, Pillemer K: Family caregiving and marital satisfaction: findings from a 1 -year panel study of women caring for parents with dementia. J Marriage Fam 1994;56:681-690.

21 Bookwala J: The impact of parent care on marital quality and well-being in adult daughters and sons. J Gerontol 2009;64:339347.

22 Ron P: Care giving offspring to aging parents: how it affects their marital relations, parenthood, and mental health. Illness Crisis Loss 2006;14:1-21.

23 Stephens MP, Franks MM: Spillover between daughters' roles as caregiver and wife: interference or enhancement? J Gerontol 1995;50 9-17.

24 Grote NK, Naylor KE, Clark MS: Perceiving the division of family work to be unfair: social comparisons, enjoyment, and competence matter? J Fam Psychol 2002;16:510522 .

25 Goldberg AE, Perry-Jenkins M: Division of labor and working-class women's well-being across the transition to parenthood. J Fam Psychol 2004;18:225-236.

26 Kulik A: Perceived equality in spousal relations, marital quality, and life satisfaction: a comparison between elderly wives and husbands. Fam Soc 2004;85:243-250.

27 Pennsylvania State Data Center: Research brief: new standards for defining metropolitan statistical areas announced. Harrisburg, Institute of State and Regional Affairs, 2001.

28 Umberson D: Relationships with children: explaining parents' psychological well-being. J Marriage Fam 1989;51:999-1012.
29 Vaux A: Social support: theory, research, and intervention. New York, Praeger Publishers, 1988.

30 Silverstein M, Gans D, Yang FM: Intergenerational support to aging parents: the role of norms and needs. J Fam Issues 2006;27: 1068-1084.

31 Henretta JC, Grundy E, Harris S: The influence of socio-economic and health differences on parents' provision of help to adult children: a British-United States comparison. Aging Soc 2002;22:441-458.

32 Rovine MJ, von Eye A, Wood P: The effect of low covariate criterion correlations on the analysis-of-covariance; in Wegmen E (ed): Computer Science and Statistics: Proceedings of the 20th Symposium of the Interface. Alexandria, American Statistical Association, 1988, pp 500-504.

33 Laird NM, Ware JH: Random-effects models for longitudinal data. Biometrics 1982;38: 963-974.

34 Griffin D, Murray S, Gonzalez R: Difference score correlations in relationship research: a conceptual primer. Personal Relationships 1999;6:505-518.

35 Eggebeen DJ, Davey A: Do safety nets work? The role of anticipated help in times of need. J Marriage Fam 1998;60:939-950.

36 Bengtson VL: Beyond the nuclear family: the increasing importance of multigenerational bonds. J Marriage Fam 2001;63:1-16.

37 Stoller EP: Gender differences in the experiences of caregiving spouses; in Dwyer J, Coward RT (eds): Gender, Families, and Elder Care. Thousand Oaks, Sage Publications, 1992, pp 49-64.

38 Kivett VR: Consanguinity and kin level: their relative importance to the helping network of older adults. J Gerontol 1985;40:228234

39 Henz U: Couples' provision of informal care for parents and parents-in-law: far from sharing equally? Ageing Soc 2009;29:369395. 